\title{
Saudi Enterprise and Critical Success Factors
}

\author{
Mohammed I. Al Aattas and Kyeong Kang \\ University of Technology, Sydney, Australia \\ Correspondence should be addressed to: Mohammed I. Al Aattas; \\ Mohammed.I.Alattas@student.uts.edu.au
}

Received date: 5 September 2014; Accepted date: 13 December 2014; Published date: 7 September 2015

Academic Editor: Lee Seung Ho

Copyright (C) 2015. Mohammed I. Al Aattas and Kyeong Kang . Distributed under Creative Commons CCBY 4.0

\begin{abstract}
The importance of the business systems is ever increasingly, as the new and innovative systems are being used by organizations to improve their competitiveness. Based on the literature review, this research identifies four factors that can impact the success of new business systems in Saudi enterprise. However, the role of culture also cannot be neglected in the Saudi firms which aim to improve their businesses systems. This research is proposing a conceptual model that describes the culture impact on the success of new business systems in Saudi enterprises related to collaboration and IT experience, and the characteristics related to IT systems: usefulness and efficiency.
\end{abstract}

Keywords: Culture, Business Systems, Collaboration, IT experience, Usefulness

\section{Introduction}

The level of competition and the complexity of the new business systems often mean that the organizations need to improve their efficiency and effectives. One of the key issues is the culture, which is defined as the way in which the organizations is able to develop its stories, rituals and other daily routines. One of the factors which have been highlighted is that, the employee culture can be an important aspect of the development of the ways in which the organization can improve over time (Hu et al., 2012). The importance of culture is increasingly important for the organizational actors, as the actors need to be able to define the organizational needs. In particular, one of the issues which have been highlighted in the literature on the Saudi enterprises is that the understanding of the culture issues on the organizational systems has not been highlighted, and therefore there is a need to understand these issues in more detail (Adlan and ten Have, 2012).

Managers in Saudi business organizations need to have a clearer understanding of the needs of the organization, and the new businesses systems are increasingly important for the organization (Liu et al., 2007). Organizations around the world have been able to gain substantial amount of independence due to the information systems which can bring in a competitive advantage

Cite this Article as: Mohammed I. Al Aattas and Kyeong Kang (2015)," Saudi Enterprise and Critical Success Factors ", The Journal of Organizational Management Studies, Vol. 2015 (2015), Article ID 742945, 
for the organization. The importance of business systems is also significant, as the stakeholders and business managers need to ensure that the effect of culture on the employees can be established (Juntiwasarakij, 2008). The efficiency of the organizational actors is one of the most important aspects in this regard, as the organizational actors need to ensure that they have the appropriate systems put into place, which can work to establish the demands of their organizational actors ( Lee et al., 2012,). The businesses systems are today being integrated to improve the efficiency of the organizations, and to ensure that the stakeholders are able to deliver the needs of the organization (Juntiwasarakij, 2008). Organizations need to ensure that they can measure the effect of culture on the business system success (Jalal et al., 2011). This research examines some of these important issues within literature, such as collaboration, IT experience, efficiency and usefulness on the success of business system in Saudi enterprise.

\section{Problem Statement}

A number of studies have examined the issues of culture, but its relation to the way in which the businesses processes work and relate is also important to consider, and therefore needs to be evaluated (Liu et al., 2007). The research problem also needs to be understood in the Saudi context. In Saudi Arabia, the organizations do not focus on the way in which the culture of the employees and the organizations are influenced by the different factors (Adlan and ten Have, 2012). The importance of the culture cannot be overlooked due to its impact on success of any organization. Culture has an important influence on the business systems in Saudi organizations (Shao et al., 2013). The cultures can influence the efficiency and the effectiveness of the organizational actors. Another factor is that the organizational actors need to ensure that they have robust mechanisms, put into place, which can ensure that the organization is able to improve significantly. The businesses systems of the
Saudi organizations need to improve considerably, and therefore there is a need for the organizations to ensure that the collaboration can be enabled (Beauregard, 2011). The organizations also needed to ensure that they have the best possible IT systems available to them, which can lead to a competitive advantage for the firm (Cloin et al., 2011).

Many large organizations moved to the Middle East to apply new technologies but not all of them are successful and go back to traditional ways. This research will investigate the important factors, and to determine the culture of Saudi and non-Saudi employee that how it will effect on the success of new Business systems. This research will company manager to take into account the culture of Saudi and non-Saudi employee to get benefits from the new technologies.

\section{Related Studies}

\section{Cultural Impact on New Business Systems Success}

The term culture has been defined as the collective behavior of people within an organization setting and the meanings they associate to actions (Fong and Kwok, 2009). These shared mental assumptions by individuals in an organization includes norms, values and ways of thinking (Shepstone and Currie, 2008). A number of authors have contended that organization needs are imperative to be defined, this is because needs of an organization will determine culture that bests serves its needs (Shao et al., 2012). International culture is the standard set of beliefs and norms that are followed by organizations across the board. The challenge that companies now face is to keep up with the pace of changing international culture, in order to cater to the customers (Luis Ballesteros-Rodriguez et al., 2012). Companies are now spending millions to have an ongoing research about that the changing culture and train their beliefs with the external demands (Inazawa, 2009). One 
of the key issues in this regard is that this research is especially important as stakeholders, need to ensure that the culture of the organization is well under stood, especially in Saudi Context which is often problematic (Adlan and ten Have, 2012). An important challenge that arises for the organizations is to clearly understand the needs of their organization and change their norms according to their needs, on their way to success (Henk, 2007). Taking the example of Saudi Arabian organizations, managers need to ensure that employees follow the set of beliefs that are followed all around the world, so that Saudi Arabian companies can be on the learning curve. Culture has not just been advocated as the widely held belief systems by employees within an organization, but something more beyond that. The set of beliefs that employees follow are set by the leaders of organization (Ifinedo, 2007). Getting high quality products at the minimum most cost is all due to the following cultural beliefs (Passos et al., 2012). It has been discussed that quality, culture, productivity and good management are all linked (Shao et al., 2012). One of the arguments is that, high productivity is a result of motivation among employees, which further results in good climate for work (Stock et al., 2007). A good climate that is a result of good management will result in organization clarity, well defined structure for decision making and integration of different organization's parts, and amalgamation of different cultures into a unified culture that reflects leader's vision.

Factors Impacting the Success of Implementing New Business Systems

Collaboration is considerably important as the organizations need to ensure that they have the best possible system available to them, which can ensure the long term success (Kratzer et al., 2011, Roggeveen et al., 2012). IT experience is not only important for the smooth running of organization but it is also one of the core businesses premise for organizations success (Adya, 2006). One best way in which IT can be used for company success is the flexibility of the IT that is incorporated in organization (Von Wurtemberg et al., 2011). In most cases, IT systems are standalone systems, without any ability of integration. In this way, different businesses processes are operating in silo which deters success of organization (Robison et al., 2007). One of the other factors which need to be taken into account in this respect is that the organizational actors have to ensure that they have the best systems put into place, which can enable the actors to develop and understand the issues of efficiency (Jun and Kim, 2010). Usefulness is also important in the success of business systems in order to ensure that the organizational actors are able to work progressively (Kaptein, 2011).

\section{Collaboration}

The importance of the collaboration is critical to the way in which the employees can lead to the success of the organization, as organizations need to ensure that they are giving the best possible customer service (Worasinchai \& Bechina, 2009). A number of authors have highlighted the fact that gathering knowledge about the staff, their customers and demands is central to the success of a company (Kratzer et al., 2011). The way collaboration can be successfully shared is through different IT systems, where all relevant parties receive data about customers demand and expectations (Elenurm, 2012). Collaboration has an important influence on the way that the organizations work (Buckley and Giannakopoulos, 2010).

\section{IT Experience}

Another recommended way of use of IT is its ability to share important information and knowledge about customers choices (Robison et al., 2005). The way success is embedded in the use of IT system is that, newer ways of doing work will be initiated with the integration of IT system (Shutov, 2011). The implementation of new systems is often dependent on the way that the organizational 
actors are able to implement the systems, and therefore the acceptance of new innovation is highly important for the organization (Chen and Chen, 2010). The tasks that were carried out with human capital can now be performed with a minimum number of employees (Ozcelik, 2013). This also reduces the costs and expenses of organization (Tsai et al., 2009).

\section{Efficiency and Usefulness}

Efficiency is one of the dominant issues for organizations; in order to ensure that they can remain competitive (McCarthy, 2009). The internal organizational efficiency, when taken as part of the organizational structure and part of the culture of the employees, can lead to long term competitive gains for the organization, and also ensure that the organization can be competitive as compared to their opponents (Netesanyi, 2008). The culture of the organization also needs to be established in a way where the organizations have the best possible system which can deal with the needs of the organizations (Bahqat, 2006). Considering the role of information systems and the way in which its usefulness to customers can be enhanced, is that useful information regarding customers' demands can be held onto computers, which can later be incorporated into business strategy (Mitsuhashi et al., 2008).

\section{Approach}

\section{Aim}

The aim of this study is to investigate the success factors which need to be taken into account to establish a clear road for the organizations to gain a competitive advantage through culture. The literature analysis provides an empirical evidence for the success of business systems factors in Saudi enterprise. A conceptual model is then presented which describes the importance of different factors on the success of collaborative business systems in Saudi context.

\section{Research Question}

What are the significant factors that impact the success of new business systems in Saudi enterprise?

\section{Research Model}

Based on the examining of the existing literature, we proposed a framework by describing the success of business systems in Saudi enterprises related to staff characteristics such as, collaboration and IT experience, and the characteristics related to IT systems such as, usefulness and efficiency. And the culture is a moderating variable (Figure 1). The keywords used in this search are: Collaboration; IT experience; Efficiency; Usefulness and Culture. 


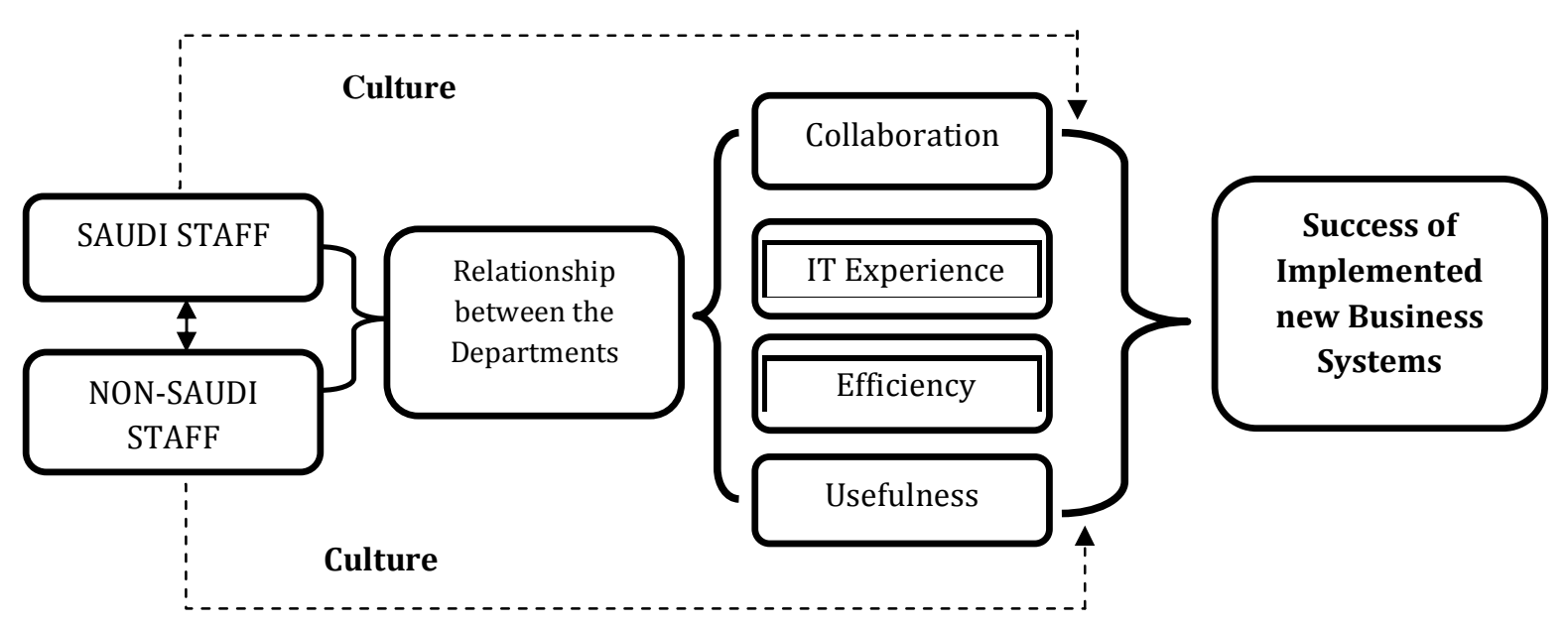

Figure 1: Success Factors Affecting Implemented Business System in Saudi Enterprise

\section{Success Factors Affecting the New Business Systems}

\section{Collaboration}

One of the factors which are significantly important for the organizations is the use of information systems to increase the collaboration (Boehm, 2012). Although, collaboration may be an understood concept in the private organizations, however in many organizations in Saudi, these factors have not been well understood, and therefore can create a number of issues for the organizational actors. The impact of the organizations systems on the organizational actors can also mean that the actors are able to not only implement the systems, but also collaborate to improve their efficiency and effectiveness. Collaboration among different business individuals is of significant importance. The idea that is embedded in collaboration is the notion of collecting and sharing all relevant data among different business entities, so that, companies can have a better understanding of their customers (Vuori and Okkonen, 2012). The working together of the employees is also considerably important for the organizations, as the stakeholders need to ensure that they have the systems available to them. In particular, related to Saudi enterprises.

\section{IT Experience}

Another factor, which is of critical importance, is the level of IT experiences that it relates to the different stakeholders (Lee et al., 2012). Innovations in the organization are only possible where organization culture, and the adaptation of new technologies are brought together, which can ensure that the different stakeholders can work to deliver on the best possible work routines for the employees (Mian, 2011a). The lack of acceptance of the new IT innovations for the actors can lead to a number of issues and problems for the organizational managers (Chen and Chen, 2010). IT experiences of the staff are linked with the success of the businesses systems (Boehm, 2012). The businesses systems in Saudi Arabia are linked with the way in which the organizational actors are able to have a clear definition of the issues (Lee et al., 2012). This is also important to consider, as the organizations 
will have to ensure that they are able to have a robust mechanism ( Rouchy, 2012).

\section{Efficiency and Usefulness}

The most important element is the way that the organizations can continue to have a system, which can improve their organizational effectiveness (Zhao, 2004). Managers need to understand that companies that make efficient systems enjoy success of their organizations (Kleine, 2008). Another factor, which is critically important for the organization, is the usefulness of the IT systems. This can have a number of benefits for the organizational environment, as the organizational actors can ensure that they have the usable systems put into place, leading to long term benefit for the organizations. In the case of Saudi organizations, the usefulness of the IT systems needs to be put within the cultural environment of the organizations in order to ensure that the organizations are working in an efficient and effective manner. This also needs to be undertaken in order to ensure the long term success of the organizational actors (Kim, 2008). Culture in Saudi organizations need to be more vigilant and responsive towards changes in demand, so that usefulness can be benefit with the use of new business systems.

\section{Conclusion and Future work}

The culture of the employees can affect the success of the business systems in Saudi enterprise, as they need to develop a complete understanding of the difficulties that the organizations face in relation to the systems. Collaborative environment is influenced by the culture of the organizations and due to the limitations of studies in the Western countries; these issues cannot be directly extrapolated to Saudi context. Another variable, which is considerably important, is the efficiency of the organizations, which needs to be measured in relation to the usefulness of new business systems.
The above factors are important on the success of business systems in Saudi enterprises. It will allow company managers to improve the organizational effectiveness in terms of using new business systems. This study extends the theorization of existing studies that will allow researcher to understand more about the different factors that impact the success of new business system in particular culture.

This work has some observable limitation. A mixed-method approach is necessary to measure and statistically test the above factors on the success of new business system in Saudi enterprise.

\section{References}

1. ADLAN, A. A. \& TEN HAVE, H. A. M. J. 2012. The Dilemma of Revealing Sensitive Information on Paternity Status in Arabian Social and Cultural Contexts. Journal of Bioethical Inquiry, 9, 403-409.

2. ADYA, M. P., S. O. C. 2006. Imparting global software development experience via an IT project management course: Critical success factors. 30th Annual International Computer Software and Applications Conference, Vol 1, Regular Papers/Panels, Proceedings.

3. BAHQAT, G. 2006. Nuclear proliferation: the case of Saudi Arabia. The Middle East journal, 60, 33-37.

4. BEAUREGARD, T. A. 2011. Direct and Indirect Links Between Organizational WorkHome Culture and Employee Well-being. British Journal of Management, 22, 218-237.

5. BOEHM, E. 2012. Improving Efficiency and Effectiveness in an Automotive $R \& D$ Organization How a Traditional R\&D Division Reshaped Itself Into a High-Performance Organization.

Management, 55, 18-25.

6. BUCHANAN-OLIVER, M. \& CRUZ, A. 2009. The Body and Technology: Discourses 
Shaping Consumer Experience and Marketing Communications of Technological Products and Services. In: MCGILL, A. L. \& SHAVITT, S. (eds.) Advances in Consumer Research, Vol Xxxvi.

7. BUCKLEY, S. \& GIANNAKOPOULOS, A. 2010. Sharing Knowledge in a Knowledge City Using CoPs.

8. CHEN, H. \& CHEN, Y. 2010. Research on Family Business' Social Responsibility to Employees: A Strategic Thinking of Family Culture.

9. CLOIN, M., KEUZENKAMP, S. \& PLANTENGA, J. 2011. A matter of culture and cost? A comparison of the employment decisions made by mothers with a lower, intermediate and higher level of education in the Netherlands. Work Employment and Society, 25, 468-486.

10. ELENURM, T. 2012. Open space as a knowledge metaphor and a knowledge sharing intervention. Knowledge Management Research \& Practice, 10, 55-63.

11. FONG, P. S. W. \& KWOK, C. W. C. 2009. Organizational Culture and Knowledge Management Success at Project and Organizational Levels in Contracting Firms. Journal of Construction Engineering and Management-Asce, 135, 1348-1356.

12. HENK, D. 2007. Organizational Culture and Antipoaching Success.

13. HU, Q., DINEV, T., HART, P. \& COOKE, D. 2012. Managing Employee Compliance with Information Security Policies: The Critical Role of Top Management and Organizational Culture. Decision Sciences, 43, 615-659.

14. IFINEDO, P. 2007. Interactions between organizational size, culture, and structure and some it factors in the context of ERP success assessment: An exploratory investigation. Journal of Computer Information Systems, 47, 28-44.
15. INAZAWA, F. K. 2009. Understanding organizational culture and learning processes for the success of the knowledge management. Perspectivas Em Ciencia Da Informacao, 14, 206-220.

16. JALAL, H. A., TOULSON, P. \& TWEED, D. 2011. Exploring Employee Perceptions of the Relationships Among Knoledge Sharing Capability, Organisational Culture and Knowledge Sharing Success: Their Implications for HRM Practice.

17. JUN, T. \& KIM, J.-Y. 2010. Designing the Efficient Information-Processing Organization. B E Journal of Theoretical Economics, 10.

18. JUNTIWASARAKIJ, S. 2008. The Impact of IT Outsourcing Practice on Employment Culture: An IT Professional's Perspective.

19. KAPTEIN, M. 2011. From Inaction to External Whistleblowing: The Influence of the Ethical Culture of Organizations on Employee Responses to Observed Wrongdoing. Journal of Business Ethics, 98, 513-530.

20. KIM, S. H. 2008. Moderating effects of Job Relevance and Experience on mobile wireless technology acceptance: Adoption of a smartphone by individuals. Information \& Management, 45, 387-393.

21. KLEINE, A. 2008. Efficiency Measurement of Organizations in Multi-Stage Systems. In: KALCSICS, J. \& NICKEL, S. (eds.) Operations Research Proceedings 2007.

22. KRATZER, J., GEMUENDEN, H. G. \& LETTL, C. 2011. The Organizational Design of Large R\&D Collaborations and Its Effect on Time and Budget Efficiency: The Contrast Between Blueprints and Reality. Ieee Transactions on Engineering Management, 58, 295-306.

23. LEE, L., MEYER, T. \& SMITH, J. S. 2012. Reinventing the Customer Experience: Technology and the Service Marketing Mix. 
24. LIU, G., DAI, C. \& ALFRED, U. 2007. Path diagram analysis of organizational shared knowledge effects on organizational performance.

25. MCCARTHY, G. 2009. Deliver tangible ROI. Three healthcare organizations see reduced costs, enhanced efficiency and increased compliance with CPOE systems. Health management technology, 30, 28-9.

26. MIAN, S. A. 2011. Science and Technology Based Regional Entrepreneurship Global Experience in Policy and Program Development Introduction.

27. MITSUHASHI, H., SHANE, S. \& SINE, W. D. 2008. Organization governance form in franchising: Efficient contracting or organizational momentum? Strategic Management Journal, 29, 1127-1136.

28. NETESANYI, Y. V. 2008. Industrialfinancial groups as an efficient form of business organization. Actual Problems of Economics, 89-93.

29. OZCELIK, Y. 2013. Effects of Business Process Reengineering on Firm Performance: An Econometric Analysis. In: GLYKAS, M. (ed.) Business Process Management: Theory and Applications.

30. PASSOS, O. M., DIAS-NETO, A. C. \& BARRETO, R. D. S. 2012. VOICE OF EVIDENCE Organizational Culture and Success in SPI Initiatives. Ieee Software, 29, 97-99.

31. ROBISON, L., VARDARAJULU, S. \& WILCOX, C. M. 2005. Safety and success of precut biliary sphincterotomy: Is it linked to experience or expertise. Gastrointestinal Endoscopy, 61, AB217-AB217.

32. ROBISON, L. S., VARADARAJULU, S. \& WILCOX, C. M. 2007. Safety and success of precut biliary sphincterotomy: Is it linked to experience or expertise? World Journal of Gastroenterology, 13, 2183-2186.
33. ROGGEVEEN, A. L., TSIROS, M. \& GREWAL, D. 2012. Understanding the cocreation effect: when does collaborating with customers provide a lift to service recovery? Journal of the Academy of Marketing Science, $40,771-790$.

34. ROUCHY, P. 2012. Information communication technology and economic development: Learning from the Indian experience. Papers in Regional Science, 91, 873-874

35. SHAO, R., RUPP, D. E., SKARLICKI, D. P. \& JONES, K. S. 2013. Employee Justice Across Cultures: A Meta-Analytic Review. Journal of Management, 39, 263-301.

36. SHEPSTONE, C. \& CURRIE, L. 2008. Transforming the academic library: Creating an organizational culture that fosters staff success. Journal of Academic Librarianship, 34, 358-368.

37. SHUTOV, A. 2011. Reengineering University: Modeling Business Processes to Achieve Strategic Goals. In: WRYCZA, S. (ed.) Research in Systems Analysis and Design: Models and Methods.

38. STOCK, G. N., MCFADDEN, K. L. \& GOWEN, C. R., III 2007. Organizational culture, critical success factors, and the reduction of hospital errors. International Journal of Production Economics, 106, 368-392.

39. TSAI, W.-H., YANG, C.-C., KUO, H.-C. \& IEEE 2009. Development of a Hybrid Model to Improve the Efficiency of Business Process Reengineering.

40. VON WURTEMBERG, L. M., FRANKE, U., LAGERSTROM, R., ERICSSON, E. \& LILLIESKOLD, J. 2011. IT Project Success Factors: An Experience Report.

41. VUORI, V. \& OKKONEN, J. 2012. Knowledge sharing motivational factors of using an intra-organizational social media platform. Journal of Knowledge Management, $16,592-603$. 
42. WORASINCHAI, L. \& BECHINA, A. A. A. 2009. Factors Affecting the Willingness of Multinational Corporation's to Share Knowledge with Universities: a Case Study of the Automotive Industry in Thailand.
43. ZHAO, L. P. \& WU, Y. M. 2004. The organization structure and its efficiency of project management. 